\section{Uma interpretação do Brasil como doença e rotina: a repercussão do relatório médico de Arthur Neiva e Belisário Penna (1917-1935)*}

\section{Interpreting Brazil as afflicted by disease and by the spirit of routine: the repercussion of Arthur Neiva and Belisário Penna's medical report (1917-1935)}

Dominichi Miranda de Sá

Pesquisadora do Departamento de Pesquisa e professora do Programa de Pós-Graduação em História das Ciências e da Saúde Casa de Oswaldo Cruz/Fundação Oswaldo Cruz Av. Brasil, 4036/406

21040-361 - Rio de Janeiro - RJ - Brasil dominichi@coc.fiocruz.br

Recebido para publicação em abril de 2008. Aprovado para publicação em julho de 2008.
SÁ, Dominichi Miranda de. Uma interpretação do Brasil como doença e rotina: a repercussão do relatório médico de Arthur Neiva e Belisário Penna (1917-1935). História, Ciências, Saúde - Manguinhos, Rio de Janeiro, v.16, supl.1, jul. 2009, p.183-203.

Resumo

A divulgação do relatório da viagem científica promovida pelo Instituto Oswaldo Cruz em 1912 ao Norte e Nordeste do Brasil, realizada por Arthur Neiva e Belisário Penna, suscitou debates e ocupou espaço em revistas de letras e ciências. No documento, as populações do interior do país foram caracterizadas pelas imagens de doença, isolamento, geográfico e cultural, analfabetismo, pobreza e vocação para regredir. Essas imagens do sertão foram criticadas no periódico A Informação Goiana, editado por médicos que não admitiam ser o interior definido como 'doente' e 'atrasado'. Este artigo analisa as formas pelas quais o relatório Neiva-Penna se destacou e tornou-se referência para controvérsias intelectuais sobre a questão nacional no Brasil.

Palavras-chave: viagens científicas; sanitarismo; sertão, nacionalismo; Brasil.

\section{Abstract}

The release of a report on the Oswaldo Cruz Institute's 1912 scientific voyage to North and Northeast Brazil, led by physicians Arthur Neiva and Belisário Penna, debate that found its way to the pages of magazines of the letters and sciences. The report used the images of disease, geographic and cultural isolation, illiteracy, poverty, and a vocation for backwardness to portray the people living in interior Brazil. These images of the sertão were extensively criticized in the periodical A Informação Goiana, published by local doctors who refused to see the interior defined as 'sickly' and 'backwards'. The article analyzes the ways in which the Neiva-Penna report distinguished itself, becoming a reference for intellectual controversies surrounding the national question in Brazil.

Keywords: scientific voyages; sanitarism; sertão; nationalism; Brazil. 
A s viagens científicas têm constituído, nos últimos anos, importante objeto de análise nas ciências sociais e na história. ${ }^{1}$ Nessas pesquisas trata-se de compreender as formas pelas quais 'sábios', médicos, cientistas e naturalistas, do período colonial ao século XX, construíram imagens da natureza e da população que contribuíram para a formação da própria imaginação social sobre o país (Lima, 1999). Mais especialmente, relatórios, correspondências, diários de campo e livros escritos por cientistas e naturalistas estrangeiros em expedições no século XIX, mas também documentos e representações visuais produzidos por médicos e viajantes brasileiros na passagem do século XIX para o XX vêm sendo considerados fontes fundamentais para a compreensão de temas como família, alimentação, vestuário, habitação, trabalho, gênero, vida doméstica, contrastes culturais, sociais e econômicos, influência europeia, construção da nacionalidade, civilização, modernização e desenvolvimento do país (Lima, 1999, 2007; Kury, 2001a, 2001b).

Nesses estudos sobre a produção dos viajantes, destacam-se os que se dedicam a analisar o uso de relatos de viagens científicas, sobretudo as médico-sanitárias, pela intelectualidade brasileira (Lima, 1999). Além de contribuir para o debate mais amplo acerca da utilização de fontes médicas e narrativas de viagem nas interpretações do Brasil, essas investigações envolvem também reflexões sobre as relações entre o tema da saúde, a construção do Estado nação e a institucionalização das ciências sociais no país (Castro-Santos, 1987; Lima, 1999, 2003; Hochman, 1998; Lima, Hochman, 1996, 2004). Seu principal pressuposto é o de que, na virada do século XIX para o XX, a medicina não deve ser meramente considerada conhecimento e prática científica relacionada à manutenção da saúde, mas discurso sobre a sociedade e programa visando à reforma social (Lima, Hochman, 1996; Lima, 1999; Murard, Zylberman, 1985).

A seguir esses estudos, percebe-se que nos textos dos naturalistas do século XIX predominavam o inventário do mundo natural e a descrição pormenorizada dos espécimes coletados e da interação entre seres humanos e meio ambiente (Kury, 2001a), e que, de sua parte, nos relatórios dos viajantes brasileiros da passagem para o século XX prevaleceu a ênfase na 'civilização' e na modernização do país sob a rubrica geral da 'integração nacional' (Lima, 1999).

Foram especialmente marcados por essa pauta os relatórios que resultaram das atividades de comissões de exploração, viagens e expedições científicas organizadas pelo próprio Estado brasileiro. Constituíram tanto expressões da produção científica nacional (Kury, 2001a) quanto precondições fundamentais para a própria realização dos projetos e obras de construção de infraestrutura de transportes e comunicação dirigidos à integração dos pontos mais distantes do território (Lima, 1999).

Nesse panorama inserem-se as viagens médico-científicas promovidas pelo Instituto Oswaldo Cruz (IOC) na primeira metade do século XX, com destaque para a expedição realizada por Arthur Neiva e Belisário Penna, ao Norte e Nordeste do Brasil em 1912, por requisição da Inspetoria de Obras contra as Secas, órgão do Ministério dos Negócios da Indústria, Viação e Obras Públicas. De todas as expedições realizadas pelo IOC, essa foi a de maior repercussão nos meios intelectuais, médicos e políticos brasileiros. No relatório, as populações do interior do país foram caracterizadas pelas imagens de doença, isolamento, geográfico e cultural, analfabetismo, pobreza e vocação para regredir (Neiva, Penna, 1916). 
Pesquisas anteriores dedicadas ao tema já demonstraram que a publicação desse relatório e todo o debate decorrente motivaram a fundação da Liga Pró-Saneamento do Brasil, em 1918, o movimento pelo saneamento dos sertões, a defesa da criação de postos de profilaxia rural e de educação sanitária, e, sobretudo, a campanha pela federalização dos serviços de saúde pública no Brasil, cuja maior expressão foi a criação do Departamento Nacional de Saúde Pública (DNSP) em dezembro de 1919 (Castro-Santos, 1985, 1987; Hochman, 1998; Lima, 1999; Lima, Hochman, 1996).

A repercussão do relatório, no entanto, não se restringiu à imprensa ou aos periódicos médicos nem tampouco à promoção de políticas públicas de saúde na época em que foi lançado. Seu impacto não foi fugaz. As persistentes referências ao documento, anos a fio, podem ser acompanhadas em revistas de ciências e letras nas quais as controvérsias intelectuais sobre a questão nacional no Brasil, nas décadas de 1920 e 1930, dialogaram com suas principais temáticas.

Neste artigo analiso o processo de divulgação, leitura, circulação, recepção e repercussão de relatório técnico encomendado por órgão federal, publicado como trabalho científico em importante revista médica do período e, nos anos seguintes, 'ressignificado' como panfleto nacionalista. Como explicar que ele se tenha destacado em meio a tantos outros relatórios técnicos produzidos na mesma época?

Para responder a essa pergunta, examino aqui, fundamentalmente, a 'aventura' de um texto $^{2}$, ou seja, sua produção pelos autores, mas, sobretudo, seu percurso errático nas mãos de diferentes leitores em diferentes lugares e períodos. Entre essas leituras diversas e interpretações inovadoras em relação ao sentido inicial dado pelos autores a seu texto, um resultado imprevisto: o relatório Neiva-Penna reavivou a pauta mudancista em políticos, médicos e intelectuais do planalto central do Brasil.

\section{Viagens científicas e integração nacional}

A 'integração nacional' era o emblema central do governo federal nos primeiros anos da República. Significava, basicamente, ocupar e povoar os espaços vazios, sobretudo os do interior do território, tornando-os produtivos (Maciel, 1998). Era encargo especial do Ministério dos Negócios da Indústria, Viação e Obras Públicas, ao qual cabia, por intermédio de seus órgãos e departamentos, "animar as indústrias, ajudar o desenvolvimento do comércio, construir estradas e abrir canais, regularizar, beneficiar e entreter os rios, melhorar e abastecer os portos marítimos, multiplicar e facilitar as comunicações, espalhar e vulgarizar a instrução ...". ${ }^{3}$

Visando à incorporação dos espaços afastados do interior, o próprio Estado brasileiro, na virada do século XIX para o XX, além de primordialmente promover construção e obras nos portos e estradas de ferro, organizou viagens científicas que constituíram, elas também, projetos oficiais de modernização e de exploração das potencialidades econômicas do território brasileiro. As origens desse projeto podem ser localizadas no Império, via, por exemplo, as atividades da Comissão Científica de Exploração (1856), da Comissão Geológica Imperial (1875) e da Comissão Geográfica e Geológica de São Paulo (1886) (Figueirôa, 
1997), mas, durante a República, iniciativas semelhantes não só se intensificaram como ganharam nova expressão. 'Incorporação' e 'conhecimento científico' do território - aliança que incluía, não raras vezes, levantamentos nosológicos e atividades de combate a doenças nos sítios a serem ocupados e povoados - passaram a ser aspectos absolutamente indissociáveis no interior do Ministério da Viação. Daí sua crescente associação com instituições de pesquisa como, entre outras, o Observatório Astronômico, o Museu Nacional e o Instituto Oswaldo Cruz.

Dentre essas iniciativas republicanas destacam-se a Comissão Exploradora do Planalto Central do Brasil, chefiada pelo astrônomo Louis Cruls entre junho de 1892 e março de 1893, visando à mudança da capital federal; as da Comissão Construtora de Linhas Telegráficas do Rio de Janeiro a Mato Grosso e de Mato Grosso ao Amazonas, realizadas respectivamente entre 1891 e 1906 e entre 1907 e 1915; e as expedições médico-científicas do Instituto Oswaldo Cruz (Lima, 1999).

A chamada Comissão Cruls foi nomeada durante a gestão de Floriano Peixoto na Presidência da República, com o objetivo principal de demarcar as terras que a então recém-promulgada Constituição Republicana, de 1891, previra para a construção da nova capital. Não se limitou, no entanto, à demarcação geográfica da futura capital do Brasil; realizou também estudos geológicos, além de ter produzido um 'diagnóstico médico' para toda a região do Planalto Central (Rosas, 1996; Lima, 1999; Vergara, 2006). Esse item foi especialmente desenvolvido no anexo IV do relatório final da Comissão, redigido pelo médico Antônio Azevedo Pimentel. Priorizando temas como topografia, hidrografia, geologia, vegetação, climas e doenças endêmicas da região, Pimentel defendeu a extensão do povoamento do Brasil do litoral para o sertão (apoiado em observações da geografia médica, ou seja, na análise da importância do meio ambiente para o aparecimento e distribuição de doenças), pois, segundo ele, ao contrário do que comumente se acreditava, as terras do interior seriam muito férteis e salubres.

Como exemplo ainda mais eloquente dessa aliança entre ciência e integração territorial, pode-se citar a Comissão Construtora de Linhas Telegráficas Estratégicas, mais conhecida como Comissão Rondon e que ficou marcada, principalmente, pelas atividades que deram origem a políticas indigenistas (Maciel, 1998; Bigio, 2000; Souza Lima, 1995). Ocorridas ao longo de mais de vinte anos, as viagens empreendidas por militares brasileiros do setor de engenharia e construção do Exército também caminharam no sentido da integração do interior do país. Nessas expedições foram efetivados, sobretudo, trabalhos de instalação e conservação de linhas telegráficas e serviços de demarcação e inspeção das fronteiras brasileiras. Enquanto estendiam fios telegráficos para possibilitar a comunicação entre os centros urbanos e o interior do Brasil, no entanto, os membros da Comissão, entre eles vários naturalistas, sobretudo do Museu Nacional, empreenderam também a exploração científica do território, com ênfase no conhecimento da geografia do país. Esse trabalho, feito primordialmente nas viagens do período 1907-1915, deu origem a uma centena de relatórios e teve grande importância em áreas diversas como a cartografia, a botânica, a geologia, a zoologia, a antropologia e a etnografia de populações indígenas e sertanejas (Lima, Sá, 2006, no prelo; Sá, Sá, Lima, 2008). 
Quanto às viagens científicas promovidas pelo Instituto Oswaldo Cruz, ocorreram quando a instituição, na primeira década do século XX, passou a colaborar com a Secretaria dos Negócios da Agricultura, Comércio e Obras Públicas do Ministério Viação, promovendo expedições ao interior que, comandadas por seus principais médicos e cientistas, acompanharam obras de infraestrutura, como a construção de ferrovias e a inspeção sanitária de portos, e a extração de borracha na Amazônia (Lima, 1999). Foi o caso, por exemplo, das primeiras viagens médico-científicas, de pequeno porte, que visavam reverter quadros epidêmicos em áreas restritas e que tiveram início em 1906. Nesse ano, Carlos Chagas foi enviado a São Paulo para debelar um surto de malária na região em que a Companhia Docas de Santos construía uma usina hidrelétrica. Logo depois, ainda no mesmo ano, ao lado de Arthur Neiva e Rocha Faria, Chagas promoveu nova campanha contra a malária em Xerém, na Baixada Fluminense, onde eram construídos reservatórios de água, pela Inspetoria Geral de Obras, para o abastecimento da cidade do Rio de Janeiro. Em 1907, Arthur Neiva atuou em São Paulo, a serviço da Estrada de Ferro Noroeste do Brasil, enquanto Carlos Chagas e Belisário Penna seguiram para Minas Gerais, para, igualmente, dar combate à malária que dificultava os trabalhos de prolongamento da Estrada de Ferro Central do Brasil (Albuquerque et al., 1991; Lima, 1999; Kropf, 2006).

Em 1910, Oswaldo Cruz realizou a inspeção sanitária das obras da usina hidrelétrica que a Cia. Light and Power construía em Ribeirão das Lages, no estado do Rio de Janeiro, tendo seguido, logo depois, com Belisário Penna, para a Amazônia, a convite da MadeiraMamoré Railway Company (Cruz, 1910; Schweickardt, Lima, 2007).

Outra viagem em que avultava a associação de ciência e integração territorial foi a de Carlos Chagas, Pacheco Leão e João Pedro de Albuquerque, em expedição requisitada pela Superintendência da Defesa da Borracha. Entre outubro de 1912 e março de 1913, esses médicos ocuparam-se em avaliar as condições sanitárias e de vida dos principais centros de produção da borracha, percorrendo, entre outros, os rios Solimões, Juruá, Purus, Acre, Iaco, Negro e o baixo rio Branco. A seguir as demandas da Superintendência, vemos que a expedição tinha como principal objetivo o levantamento epidemiológico da região, de modo a garantir a posterior exploração de seus recursos naturais (Albuquerque et al., 1991; Lima, 1999; Kropf, 2006; Schweickardt, Lima, 2007).

As viagens científicas do IOC na ocasião também se realizavam em função das demandas da Inspetoria de Obras contra as Secas, órgão do Ministério da Viação criado em 1909 com o intuito de avaliar o potencial econômico dos rios, construir açudes e inventariar as condições climáticas, epidemiológicas e socioeconômicas do Nordeste e Centro-Oeste brasileiros (Santos, 2003). Mais especificamente, cabiam aos membros das expedições ligadas ao Instituto o reconhecimento topográfico e o levantamento sanitário das regiões secas, assim como o compromisso de preparar relatórios com os resultados de suas viagens. ${ }^{4}$

Esse foi o objetivo da viagem científica a Piauí, Pernambuco, Bahia e Goiás organizada por Arthur Neiva e Belisário Penna, em 1912. Como a expedição de Carlos Chagas à Amazônia, a de Neiva e Penna também estava inserida em proposta de integração nacional (Lima, 1999) e, em seu relatório, temas como o desconhecimento do real valor do sertão brasileiro e a incorporação das populações do interior eram igualmente apresentados como elementos primordiais da agenda política e científica do país. 


\section{O relato da expedição ao interior}

Em consonância com a Inspetoria de Obras contra as Secas, a expedição comandada por Arthur Neiva e Belisário Penna tinha por objetivo conhecer e mapear o quadro nosológico do norte da Bahia, sudoeste de Pernambuco, sul do Piauí e de Goiás de norte a sul. Durante sete meses, entre abril e outubro de 1912, os médicos estudaram fauna, flora, geografia, condições de vida e história das localidades que percorreram em lombo de burro de modo a melhor compreender a incidência e a distribuição de determinadas doenças e a propor medidas profiláticas para seu combate. Tratava-se de incrementar o potencial produtivo daquelas regiões visando a sua modernização. ${ }^{5}$

Baseado em riqueza de exemplos, com recurso a depoimentos dos habitantes das regiões percorridas e mais de uma centena de fotografias, o diário apresenta autêntica 'etnografia' do modo de vida das populações interioranas do Brasil no início do século XX (Lima, 1999, 2003). Segundo o relato de Neiva e Penna, sertanejos seriam atrasados, indolentes, fatalistas e fracos não por qualquer insuficiência decorrente de cruzamentos raciais (pauta central do debate sobre a identidade nacional no século XIX), mas porque sofreriam de doenças plenamente evitáveis, como ancilostomose, impaludismo e doença de Chagas, sobretudo no então norte de Goiás, região hoje conhecida como o estado do Tocantins. Em seu desenho, as doenças seriam o maior obstáculo ao progresso do Brasil (Lima, Hochman, 1996).

O relatório apresenta ainda outras fortes caracterizações - os homens do interior não passariam de doentes abandonados e esquecidos pelo restante do Brasil, e o sertão seria marcado pela vastidão, por baixa densidade demográfica, resistência às mudanças, dificuldades de estabelecimento de bases mínimas de nacionalidade (devidas à ausência de meios de transporte e de vias de comunicação com o litoral), e analfabetismo presumido em 95\%. Somem-se ainda ausência da autoridade pública, pobreza, apatia, espírito de rotina, impenetrabilidade ao progresso, vocação para regredir, primitivismo, culto da dignidade, probidade, moralidade do lar, zelo pela honra pessoal, mas também desatenção às leis e recurso à resolução violenta dos conflitos (Neiva, Penna, 1916).

Enfatizavam também que era mínima a presença de médicos em vastas extensões do interior do território brasileiro, e, portanto, mínima também sua expressão como agentes de cura para a maioria da população do sertão, de onde resulta o seu retrato do Brasil como país doente, abandonado e, por isso mesmo, atrasado. Defenderam, assim, a presença crescente de médicos nessas áreas isoladas, pois, de acordo com suas conclusões, o correlativo lógico dessa falta de assistência era o amplo recurso à chamada 'terapêutica popular' (Neiva, Penna, 1916).

O relatório foi muito discutido em jornais do Rio de Janeiro, sobretudo n'O País e no Correio da Manhã, em 1917 e 1918, e mesmo na época, como de fato sugere a bibliografia, tornou-se referência incontornável para a discussão sobre a identidade nacional (CastroSantos, 1985, 1987; Hochman, 1998; Lima, 1999, 2002; Lima, Hochman, 1996, 2004). No processo de repercussão de seus principais temas, foi apontado como marco de origem da campanha nacionalista pelo saneamento rural e seguidamente relacionado ao Jeca Tatu de Monteiro Lobato, principal representação do homem doente do interior, anemiado e inapto para o trabalho na agricultura, e à satírica expressão de Mario de Andrade, em 
Macunaíma, sobre a situação sanitária do país: "Pouca saúde, muita saúva: os males do Brasil são" (Lima, 2002; Lima, Hochman, 2004).

Mais decisiva, no entanto, foi sua associação ao famoso discurso proferido por Miguel Pereira, em outubro de 1916, na Faculdade de Medicina do Rio de Janeiro, no qual enfatizou que o interior do Brasil não passaria de "um imenso hospital". Apesar de pronunciado antes da publicação do relatório (Kropf, 2006, p.110), o discurso de Miguel Pereira foi sendo, nos anos 1920, crescentemente interpretado como tributário e herdeiro do diagnóstico de Neiva e Penna para o país. A que se deve essa 'inversão cronológica', nascida, na verdade, da circulação e repercussão do documento - processo que fez dele outro produto, não mero relatório técnico encomendado, como era regra, por um Ministério?

Essa pergunta tem sua pertinência redobrada se lembrarmos que as mais importantes e contundentes imagens do relatório, já mencionadas, a despeito de terem sido apresentadas e ratificadas, na época, como inéditas interpretações do Brasil (de onde adviria, aliás, sua força persuasiva e de adesão, política e intelectual), não eram propriamente novas. E, nesse caso, não me refiro apenas às célebres e contundentes imagens do livro Os sertões lançado em 1902 por Euclides da Cunha e no próprio período relacionadas ao relatório como a dos 'dois brasis', ou a polaridade entre sertão e litoral, e a do isolamento dos sertanejos ou de seu "exílio na própria pátria". Não exatamente a essas imagens. Refiro-me, mais especificamente, à insistência com que o cientista Carlos Chagas relacionava, desde o início da década de 1910, endemias rurais à degeneração do país ou, melhor, como salientava que as doenças seriam o maior obstáculo ao progresso do Brasil (Kropf, 2006). Refiro-me também aos relatórios das expedições da Comissão Rondon, nos quais os sertanejos eram apresentados como 'doentes' (Diacon, 2006). Nos relatórios dos membros da Comissão Telegráfica e em artigos na imprensa sobre suas expedições (sobretudo no Almanack Garnier e no Jornal do Commercio), o Brasil do interior era apresentado como incógnito, desconhecido, abandonado, em suma, um espaço isolado que precisaria ser efetivamente integrado ao restante do país. No mais, o 'espírito de rotina' e a ociosidade foram temas associados à existência miserável dos homens do interior em muitos relatos dos viajantes oitocentistas que percorreram o Brasil. Em Saint-Hilaire, por exemplo, são recorrentes as referências ao trabalho realizado de forma totalmente assistemática com vistas tão somente à subsistência (Barreiro, 2002).

Nem mesmo o caráter sociológico do relato Neiva-Penna (Castro Santos, 1985, 1987; Hochman, 1998; Lima, 1999; Lima, Hochman, 1996) pode ser considerado inédito ou tomado como único fundo explicativo do considerável impacto que experimentou nas décadas de 1920 e 1930 no meio intelectual brasileiro. Podem ser facilmente encontradas em textos médicos, desde a primeira metade do século XIX, análises e extensas considerações sobre a vida social brasileira no período, com ênfase em temas como família, trabalho, alimentação, costumes e habitação; o que, aliás, levou Gilberto Freyre a qualificar os médicos, em artigo publicado em O Jornal, como os "precursores esquecidos dos estudos sociológicos no Brasil" (Freyre, 21 jul. 1942, citado em Lima, 2007).

Mesmo relatórios anteriores produzidos pelo próprio Instituto Oswaldo Cruz - como, por exemplo, "Condições gerais sobre as condições sanitárias do Rio Madeira", escrito por Oswaldo Cruz em 1910 - também oferecem reflexões de caráter sociológico sobre as condições de vida das populações da região (Schweickardt, Lima, 2007). 
Por tudo isso, deve-se sugerir que derivam de uma conjunção de fatores a força interpretativa do relatório e sua persistência como fonte de compreensão dos males do Brasil, com repercussões nas obras de, entre outros, Roquette-Pinto, Gilberto Freyre, Fernando de Azevedo, Florestan Fernandes, Antonio Candido, Emílio Willems e Samuel Pessoa nos anos 20, 30 e 40 (Lima, 1999, 2007). Fato é que, nesse movimento de recepção do texto, a caracterização negativa do sertão apresentada por Neiva e Penna (em contexto político de forte marca nacionalista como o do auge da Primeira Guerra Mundial), a despeito de não ser novidade, foi mobilizada, segundo as representações da época, como novíssima visão sobre o interior e seus habitantes, como a grande 'redescoberta do país', só comparável a Os Sertões de Euclides da Cunha. A ponto de vários intelectuais afirmarem que a dita 'verdadeira situação' - de doença, miséria e abandono - das populações sertanejas só teria sido conhecida por intermédio da leitura e propaganda do relatório.

Outro dado significativo quanto a essa questão refere-se à data de publicação do texto. Apesar de assim estar referenciado originalmente, e nas próprias Memórias do Instituto Oswaldo Cruz, onde foi pela primeira vez publicado, o relatório não foi editado em 1916. São consequentes afirmações esparsas nos artigos publicados em revistas e que asseguravam estar Arthur Neiva fazendo circular, desde os primeiros meses de 1917, cópias do relatório que teria ficado pronto em 1915, aparentemente não foi enviado ao Ministério da Viação ${ }^{6}$, e, segundo presumimos, só foi mesmo publicado em 19187, quando a edição de Memórias passou a ser citada e resenhada nas revistas.

Esses novos elementos não invalidam a interpretação corrente de que da circulação do relatório derivaram a criação da Liga Pró-Saneamento do Brasil e a campanha pelo saneamento rural. Certo é, no entanto, como já afirmei, que Neiva distribuiu a seus pares, a começar por Rio de Janeiro e São Paulo, cópias do relatório, e elas passaram a ser lidas e divulgadas em jornais, como o Correio da Manhã e o Correio Paulistano, por meio de artigos escritos por Gil Vidal e por Affonso de Taunay, respectivamente, e também na Revista do Brasil, em artigos de Monteiro Lobato.

Argumento, com Kropf (2006), que o relatório não deu origem ao discurso de Miguel Pereira, mas sugiro que obteve intensa repercussão graças à combinação de três elementos: o impacto do próprio discurso de Pereira, ao qual se justapôs, o contexto nacionalista da Primeira Guerra Mundial e, sobretudo, o empenho de Neiva em divulgá-lo ao postar o texto para importantes intelectuais e cientistas da ocasião. O documento é riquíssimo e prima por considerável detalhamento nas pesquisas e nos registros, mas o modo pelo qual sua circulação inicial se realizou foi decisivo para que vários letrados a ele tivessem acesso; leitura que talvez não tivessem feito mesmo se tivesse sido publicado nas Memórias do Instituto Oswaldo Cruz em 1916.

\section{A longa viagem do relatório Neiva-Penna}

Em tom de denúncia, o Correio da Manhã na segunda-feira, 23 de outubro de 1916, publicava o primeiro artigo de uma série de textos que se seguiria praticamente ininterrupta até março do ano seguinte. Seu título era 'A eliminação do brasileiro', e, apesar de não assinado, por ter sido publicado na primeira página do periódico, como editorial, seu 
provável autor foi Gil Vidal ${ }^{8}$, redator-chefe do Correio e responsável pela maioria dos artigos similares que o jornal publicaria sobre o assunto nos meses seguintes. Nesse texto, dava notícias dos dois discursos feitos pelo médico Miguel Pereira nas semanas anteriores, em dois diferentes eventos médicos, e nos quais criticava o pronunciamento do deputado Carlos Peixoto, que declarou estar disposto a ir "de montanha em montanha, despertar os caboclos dos nossos sertões" para defender o país no conflito mundial que então se desenrolava (Lima, Hochman, 1996; Hochman, 1998; Lima, 1999). Pereira ressaltava ser tal tarefa impossível, uma vez que o interior do Brasil não passaria de "um imenso hospital", habitado, ainda em suas palavras, por "uma legião de doentes e imprestáveis". Para apoiá-lo, o jornal publicou o seguinte texto:

No meio da apatia geral que nos deixa indiferentes aos destinos do país e que nos impede de reagir em um esforço regenerador, há movimentos desordenados de ansiedade que revelam as apreensões reinantes em todos os espíritos sobre o futuro do Brasil ...

Não deixa de ser curioso notar que há poucas semanas ninguém se houvesse impressionado por uma outra forma do perigo que assedia a nossa nacionalidade ...

Hoje, que as pesquisas tão pacientes quanto brilhantes de Carlos Chagas e de Arthur Neiva vieram revelar esse sertão brasileiro tal qual ele se apresenta aos olhos do cientista e do médico, é que podemos avaliar em que camisa de onze varas nos teríamos metido, se houvéssemos transferido a sede do governo federal para o planalto central antes de estar realizada a obra colossal do saneamento do vastíssimo sertão brasileiro ...

As condições reais dessa área imensa, que a nossa imaginação tinha idealizado em um Éden de fertilidade e riqueza, foram ainda anteontem expostas em um discurso, tão belo pela forma como valioso pela substância, em que o ilustre professor Miguel Pereira saudou, como delegado da classe médica, o nosso eminente patrício Carlos Chagas. Insistindo sobre a nota que há dias vibrara em uma alocução pronunciada na Faculdade de Medicina, o professor Miguel Pereira, no seu brinde de sábado, delineou com maior riqueza de detalhes o quadro negro do inferno brasileiro. Não se trata de endemias localizadas a esta ou aquela zona do sertão, não são núcleos de população esparsos que as moléstias atacam; é a conquista do país inteiro pelas doenças, é o imperialismo da morte e da decadência, lançando as suas legiões de parasitas a destruir a nacionalidade pela eliminação lenta do homem ...

Para se poder formar uma idéia do estado dessas populações abandonadas e que estão sendo gradualmente depauperadas e eliminadas, basta dizer que somente da terrível moléstia de Chagas há mais de 1 milhão de brasileiros infectados ...

Ao presidente da República cabe promover imediatamente um acordo entre a União e os estados mais diretamente interessados, afim de que se comece a obra salvadora do saneamento do interior do país, antes de vermos o Brasil desaparecer pela extinção gradual dos brasileiros.

A rigor, o primeiro texto sobre o tema foi assinado por Gil Vidal e publicado no mesmo jornal em 16 de outubro de 1916, sob o título "Desolador, mas verdadeiro". Limitava-se, na verdade, a editar as falas do primeiro discurso de Miguel Pereira e do deputado Peixoto, com se estivessem em diálogo. Foi só logo após a publicação do texto-denúncia citado que o jornal passaria a publicar artigos em tom indignado - "O Brasil é um imenso hospital" (10 nov. 1916), "Sobre as condições de sanidade do sertanejo brasileiro" (22 nov. 1916) bem como série de textos diários de Belisário Penna intitulada "Saneamento dos Sertões" (1 nov., 17 nov., 19 nov., 20 nov. 1916). A periodicidade do assunto, o teor inflamado dos 
textos nos jornais e o protagonismo de Belisário Penna na campanha sanitarista (Lima, Hochman, 1996; Hochman, 1998) só cresceriam depois do artigo estopim de 23 de outubro, na capital federal, em menor medida em São Paulo, mas também no "sertão doente". Mencionado insistentemente por Penna como ilustração da denúncia de Miguel Pereira, o relato da viagem de 1912 ao sertão, já em fins de 1916, passava a ser referenciado como uma das provas mais contundentes da existência efetiva do 'Brasil-imenso hospital', sobretudo contra os que, na imprensa e nos meios médicos, acusavam Pereira de pessimismo exagerado e de promover campanha antipatriótica (Kropf, 2006). Tornavam-se imperativas leitura e análise de seus conteúdos, e Neiva encarregou-se da sua distribuição entre cientistas, médicos e intelectuais.

Na então capital, a consulta a revistas de ciências e letras, como, por exemplo, Revista do Brasil, Braziléia, Brasil Ilustrado, Brasil Acadêmico, Brasil Social, Brasil Moderno e Ilustração Brasileira, entre outras', permite melhor identificar a 'trajetória' do relatório, ou seja, as crescentes referências ao texto, sua circulação no meio letrado e mesmo a reformulação de seus principais temas. E foi nesse seu processo de circulação e repercussão, por exemplo, que o tema da 'doença do interior' deixou de ser considerado problema médico para ser discutido igualmente como problema político (ou sobre a urgência da incorporação dos 'sertanejos') e, em menor escala, econômico, referido à modernização do trabalho rural. De tema médico, seu debate tornou-se ainda discussão cultural definida em termos da tensão entre modos de vida tradicionais e modernos, e que, de sua parte, foi sendo compartilhada e sobretudo refinada por importantes intelectuais da época (Lima, 1999).

A esse respeito, cabe dizer que o número de revistas na cidade do Rio de Janeiro só fazia crescer naqueles anos e, com isso, elas passaram a constituir, junto com os jornais, os principais vetores da produção cultural de então, fornecendo as melhores gratificações e posições intelectuais (Sá, 2006). Nesse período, exatamente, houve aperfeiçoamento tecnológico nas tipografias da cidade, o que por sua vez permitiu aumento das tiragens dos periódicos e consideráveis inovações gráficas, como a introdução de cor e fotos (Broca, 1975; Hallewell, 1985; Gomes, 1983).

Em artigos para essas revistas, médicos, cientistas e intelectuais como Monteiro Lobato, Catulo Cearense, Ronald de Carvalho, Roquette-Pinto, Afrânio Peixoto, Amadeu Amaral, José Maria Bello, Aloísio de Castro, Álvaro Ozório de Almeida, Juliano Moreira, Cardoso Fontes, Carlos Seidl e Miguel Couto, entre outros, afirmavam que Neiva e Penna teriam fornecido subsídios 'inéditos' para a compreensão de uma parcela da população brasileira que, segundo o dizer do período, tinha vivido, por séculos, entregue a si mesma. Não surpreenderia, portanto, que se tivesse formado uma sociedade peculiar no sertão, com traços, caráter e mentalidade bem discerníveis.

A primeira e mais eloquente manifestação em São Paulo consistiu nos artigos publicados originalmente no Correio Paulistano, em 1917, e depois reunidos, em 1919, num só texto na Revista do Museu Paulista sob o título "Uma grande jornada científica: a viagem de Neiva e Penna". Seu autor, Affonso de Taunay, diretor do Museu Paulista, declarava-se bastante surpreso ao receber de seu amigo Arthur Neiva os originais de relatório inédito com os resultados de uma viagem científica que, em seu dizer, se realizou por uma tão grande quanto desconhecida zona do país. Chamando o documento de o "padrão da época", 
Taunay passa seu texto a listar suas impressões a respeito das "coisas novas", como define, que Neiva e Penna teriam descoberto sobre o Brasil, e entre outros temas, que os sertanejos seriam vítimas seculares das doenças e que estariam "ilhados" em relação ao resto do país - não pela distância geográfica, mas porque os demais brasileiros ignorariam totalmente sua existência. Salienta ainda que a amplitude das doenças nos sertões seria tão indefinida e imensa que Neiva e Penna teriam sido capazes de descobrir doenças novas, ou as "moléstias do sertão", como definiu, citando para tanto o 'vexame' e a 'entalação'. ${ }^{10}$

No texto de Taunay há ainda referências bastante recorrentes ao interesse causado pelo item "terapêutica popular" do relatório, e isso por ter revelado a escassez de recursos em que viveriam aquelas populações obrigadas a procurar na flora local meios para sobreviver às doenças. À parte isso, o recurso a rezas e a indivíduos com poderes sobrenaturais também impressionou o autor. Citando ipsis litteris o relatório tomado como verdadeiro argumento de autoridade, ele renova a narrativa em descrições enfáticas dos sertanejos que, presumindo curar-se das doenças, morderiam a chave do sacrário da igreja, beberiam sangue de galinhad'angola, usariam álcool, sal, pimenta, alho, querosene e os resíduos de alcatrão dos cachimbos em misturas com limão. Reescrevendo o relatório em linguagem mais direta e fazendo largo uso dos exemplos mais fortes quanto às doenças, à pobreza e à 'ignorância' dos sertanejos, Taunay vai definindo o sertão como o lugar em que escasseariam a água e os preceitos de higiene, servindo-se humanos e animais do mesmo líquido; e como o próprio descaso com que se deixa o "caipira boçal", totalmente ignorante e inconsciente de seus próprios problemas e erros, devastar o solo "com suas crendices, abusões, enganos e disparates de toda sorte". E completava: o sertão seria, enfim, todos aqueles "ilhados da civilização pela distância, pelo abandono dos poderes públicos, vegetando numa terra seca, parasitados por mil moléstias, paupérrimos e ignorantíssimos" (Taunay, 1919, p.520).

Outro ponto a destacar em seu texto é a forma pela qual resume a minguada alimentação dos sertanejos, restrita, em várias circunstâncias, a farinha. Sal e café seriam caríssimos e, portanto, raros; panorama em que, para mitigar a fome, haveria larga incidência de tabagismo e, sobretudo, alcoolismo. Os habitantes do sertão viveriam com parcos meios de iluminação nas residências e com vestuário rudimentar. As crianças, por exemplo, andariam nuas e descalças. A tudo isso se somariam instrução deficiente, serviço postal inoperante, falta de hospedarias, criminalidade precoce, regime penal quase inexistente e que seguia sendo substituído, não poucas vezes, pelo tronco, pela castração ou pelo assassinato. Ao fim, menciona e procura completar as soluções propostas por Neiva e Penna, como a construção de vias férreas, a açudagem, a assistência médica e a promoção do contato com o restante do país para dar aos sertanejos o gosto de progredir e também para inspirar a solidariedade dos brasileiros do litoral. Sugere a leitura urgente do relatório porque, aos demais cientistas e médicos, Neiva e Penna vieram revelar novos fatos científicos e doenças inéditas, e aos brasileiros teriam revelado aspectos 'desconhecidos' de seu próprio país.

Na Revista do Brasil - publicação paulista, mas cuja grande circulação nos meios letrados cariocas foi decisiva para sua periodicidade, longevidade e, sobretudo, reputação como canal privilegiado de produção e debate intelectuais (Luca, 1999; Sá, 2006) -, por exemplo, o tema passeava por várias seções, incluindo as Notas de Ciência, Homens e Coisas Nacionais e Resenha do Mês. Nesta última seção, em geral, eram reproduzidos e comentados artigos 
e discursos publicados nos jornais diários, e por seu intermédio pode-se atestar, mais uma vez, a grande incidência do tema na imprensa do Rio e de São Paulo.

A partir de 1917, o próprio relatório, com referências a Neiva como seu 'distribuidor'11, era volta e meia resenhado e analisado em textos com títulos bastante sugestivos, como "Os heróis do sertão" (n.20, ago. 1917, p.528-530), no qual Neiva e Penna eram comparados aos bandeirantes, ou "O saneamento do interior do país" (n.22, out. 1917, p.250-253) em que o autor, A. Amaral, ressalta as relações entre o trabalho rural e o tema mais geral da saúde. Afora Neiva e Penna, esse autor, por exemplo, cita ainda o doutor Miguel Pereira que, segundo ele, 'graças aos autores do relatório', também teria alertado para a questão da tragédia do sertanejo; problema mais sério e importante, julgava, que o próprio conflito mundial que se desenrolava na mesma época na Europa.

E o tema continuava a ser debatido em artigos como "O Brasil esquecido", de João Ribeiro (n.24, dez. 1917, p.557-559) que, depois da leitura de Neiva e Penna, passava a defender, como solução para o Brasil, a construção de estradas para o sertão, porque, em suas palavras, "elas levam de tudo, até a medicina". E completava:

\begin{abstract}
Leio, por exemplo, nesse livro (relatório) que um município extremo nos confins do Piauí é quase todo de analfabetos: os seus habitantes, sem recursos normais, sem higiene, sem assistência, sem escolas, sem caminhos de comércio, estiolam-se, depauperados pelo bócio, pelas febres, a opilação e as nevroses, mau grado a excelência do clima. Entretanto, essa população infeliz conhece a providência de um governo aladroado e infame que, despejadamente e a troco de um juíz de direito e quatro soldados de polícia, lhes arrecada para mais de CEM CONTOS de réis anuais! ... Bem se vê que o hospital dá alguma renda.
\end{abstract}

Assim, se, em 1917, os artigos publicados, na média geral de um por mês, tendem a reescrever o relatório, ampliando seus sentidos e fazendo novos usos de suas ideias, em 1918, mais especificamente, os artigos, em média três por mês, começam a debater, a retificar ou a ratificar as soluções nele propostas em franco diálogo com a Liga Pró-Saneamento do Brasil.

Nos anos seguintes, em 1918 e 1919, além dos artigos e resenhas de saudação ao livro de Belisário Penna, Saneamento do Brasil, lançado em 1918 a partir da reunião dos textos que publicara em jornais, a tendência mais marcante da Revista do Brasil, mais especificamente e, nesse caso, já em referência ao relatório publicado em Memórias do Instituto Oswaldo Cruz, era discutir a cura das doenças, mas também as maneiras possíveis de fazer frente à "cultura rotineira" dos sertanejos, tal como no texto de Mário Brant "A valorização do brasileiro" (n.27, mar. 1918, p.301-303). A discussão sobre a 'rotina' entre sertanejos também aparecia em artigos tratando "das micagens, e rezas, e burundangas, e picumans ... da terapêutica pé no chão", como chamou Monteiro Lobato em "O saneamento do Brasil" (n.27, mar. 1918, p.303-305).

Reforçam-se ainda imagens do relatório que apresentam a vida no sertão como "cortejo de horrores" ou como o "inferno de Dante", o povo do interior que vive ao "Deus dará" e que não entende o que é o governo a não ser pela cobrança de impostos; o sertanejo como um "conservador", como o portador de psicologia imóvel, ou seja, por demais apegado às tradições e refratário ao progresso e que seguiria a murmurar "é o jeito, é o jeito" (n.39, mar. 1919, p.314). Persiste também a referência à imagem dos dois brasis, do que é exemplar o texto de José Maria Bello "O problema do Brasil" (n.50, fev. 1920, p.174-175). De acordo 
com esse artigo, mais do que a doença e o abandono das populações sertanejas, o grande problema nacional seria a descompensação cultural entre as regiões do Brasil e seus modos de vida; não surpreenderia, portanto, a total ausência de vínculos sociais. Para Bello, enquanto no Rio e em São Paulo haveria conforto e civilização, o interior do Brasil não passaria de abandono, decadência, deserto, atraso e tristeza. Atualizando a imagem de Afrânio Peixoto, publicada nessa mesma revista, e para quem o sertão começaria no fim da Avenida Central (Hochman, 1998), Bello ratificava que à meia hora do coração do Rio já não se veria mais o verniz da civilização, mas somente o 'inferno dantesco' de pessoas condenadas pelas endemias, pelo alcoolismo e pelo analfabetismo. Em suas palavras, fora dos centros urbanos do Rio e de São Paulo só se veriam

\begin{abstract}
anêmicos e opilados, miseráveis que esmolam, bêbados que dormitam nas calçadas e negros semi-nus que vieram trocar a sua quarta parte de milho pelo litro de aguardente. Desgraçado Jeca Tatu! Esmagado pela natureza, hostil na sua própria exuberância, abandonado de Deus e dos homens, só conhece da vida as sensações animais e os aspectos da miséria. Nenhum desejo, nenhuma ambição agita-lhe o coração e eleva-lhe a alma; a ignorância e, dela, a superstição grosseira resumem a alegria dos sentidos no veneno do álcool e as relações do espírito à crença infantil nos feitiços e nas almas penadas. O conforto, a civilização humana estão a cinco séculos de distância. (n.50, fev. 1920, p.175)
\end{abstract}

Como, ele pergunta, todo este quadro poderia ser contemporâneo, e num mesmo país, da avenida Central, do Teatro Municipal, das docas de Santos, da civilização do litoral com seus congressos, sua justiça, os meetings do Largo da Carioca, suas academias, e "toda a entrosagem complicada das modernas sociedades políticas"? E, na sua equação, o problema não seria resolvido tão-somente com saneamento, mas, sobretudo, com instrução para que, enfim, os sertanejos se percebessem como parte integrante do solo em que nasceram.

Na revista, há textos que obedecem, em regra, a uma tradução do relatório na ratificação do 'espanto' com os altíssimos índices de incidência de doenças no interior e com o abandono em que sertanejos viveriam: "mendigos sem esperanças" (n.52, abr. 1920, p.365-366), "marginais, restos miserandos das endemias múltiplas e dizimadoras, catalogadas nos quadros nosológicos e tidas no sem-apreço ou indiferença criminosa dos governantes" (n.53, maio 1920, p.87). Do relatório se disse ainda: "livro precioso que marcará época no país pelo grande número de consequências que determinou. Todo o movimento nacional de agora saiu desse despretensioso relatório, cujo grande mérito foi dizer a verdade inteira" (n.43, ago. 1919, p.358-359). Ou "O mais eloquente testemunho do nosso atraso, do nosso relaxamento e incompetência para tudo o que diz respeito ao progresso" (n.48, dez. 1919, p.303-304).

Nos anos 20, o tema continua a aparecer em textos como "Tradição e progresso" (n.54, jun. 1920), de Luiz Araújo Correa de Brito, que discute como poderiam fazer os brasileiros para que, em suas palavras, o progresso deixasse de ser inimigo da tradição no país. Discussão semelhante aparece em "Beatos e cangaceiros", resenha para o livro de mesmo título de Xavier de Oliveira. Nele, por meio de elementos do relatório Neiva-Penna, o cangaço, também ele 'uma doença endêmica dos sertões', poderia ser explicado pela ignorância em que se atolariam os sertanejos, assim como pela falta de justiça formal, tornando ainda mais profundo o que chamou de o "desequilíbrio de séculos de civilização entre os litorâneos e os centrais" no Brasil. A tradição com seus "remédios populares", a ignorância política e 
a resistência em progredir seguem ganhando espaço ainda em "A humanidade de Jeca Tatu", texto no qual Luiz da Câmara Cascudo (n.57, set. 1920, p.84-85) faz questão de lembrar que o Jeca Tatu de Monteiro Lobato estaria longe de ser mero personagem da imaginação. E ressaltava: "o Jeca conservador das velhas tradições, o Jeca nômade, desconfiado, levando o incêndio a uma floresta para destocar meio palmo de mato, Jeca usando da prodigiosa fecundidade da terra como refúgio natural à sua doença indolente existe e é nosso contemporâneo".

A natureza exuberante vista pela literatura romântica, o clima, o bovarismo da sociedade litorânea também eram relacionados ao relatório, assim como o fora, sistematicamente, a imigração. Outros temas recorrentes foram, mais uma vez, a chamada terapêutica popular e o uso político dos postos de profilaxia rural a corroborar a 'resistência sertaneja' à presença do Estado nas áreas mais afastadas. Educação e instrução, assuntos articulados a prescrições de construção de latrinas e fossas e ao combate mais incisivo às verminoses, também apareceram atrelados ao relatório.

Nos anos e números seguintes, surge o debate sobre as relações entre saneamento e trabalho rural que logo se desprende da referência ao relatório e ganha total autonomia como discussão acerca da questão nacional. Saliente-se que os textos continuam, na década de 1930, ainda que mais espaçados (por concorrer com discussões atinentes à Revolução de 1930 e ao Estado Novo) e sem citar diretamente o relatório, a utilizar suas mais fortes e já citadas imagens. Persistem também a associação da doença ao mundo do trabalho, as discussões referidas à imagem dos dois brasis - nas quais ora o litoral é definido como moderno e o sertão como atrasado, ora o litoral é desenhado como estrangeirado, artificial e europeizado e o sertão como autêntico e genuinamente nacional. Afora isso, há discussões sobre a herança colonial, o nomadismo e os frágeis vínculos sociais entre os sertanejos, assim como a insistência na ausência de pontos de identificação entre os brasileiros. Debates sobre a ação do Estado e propostas de assistência educacional para que, por exemplo, fosse possível pôr fim ao trato "irracional e atrasado" da terra, assim como para otimizar o trabalho na lavoura eram também recorrentes. ${ }^{12}$

Como se vê, o tom panfletário-nacionalista predominou nos artigos que versavam, discutiam e/ou se reapropriavam das temáticas do relatório. No entanto, cabe fazer notar que tema muito secundário no texto publicado em Memórias ganhou enorme destaque na repercussão do documento: a chamada 'terapêutica pé no chão', imagem que resumia o espírito de rotina, a miséria, o 'realismo' e a carência de atendimento médico às populações sertanejas. Nessas discussões, passou a constituir tanto expressão suprema quanto meio privilegiado para superar os "cinco séculos de atraso" (imagem do relatório) dos 'sertanejos' em relação aos 'litorâneos' do país.

\section{A reação do'sertão doente' e a defesa do Brasil Central}

O artigo-estopim do Correio da Manhã de 23 de outubro de 1916 tornou pública a imagem do Brasil como "um imenso hospital". Como vimos, muitos médicos e intelectuais, do Rio de Janeiro e de São Paulo, lhe fizeram coro. No entanto, em Goiás, um dos estados brasileiros que compunha, geográfica e simbolicamente, o então chamado "sertão doente", um único 
trecho do mesmo artigo: "Hoje, que as pesquisas tão pacientes quanto brilhantes de Carlos Chagas e de Arthur Neiva vieram revelar esse sertão brasileiro tal qual ele se apresenta aos olhos do cientista e do médico, é que podemos avaliar em que camisa de onze varas nos teríamos metido, se houvéssemos transferido a sede do governo federal para o planalto central antes de estar realizada a obra colossal do saneamento do vastíssimo sertão brasileiro ..." - levou simplesmente à criação da revista A Informação Goiana (1917-1935), segundo o editorial de seu primeiro número ${ }^{13}$, de 15 de agosto de 1917 . Editada por médicos goianos e militares egressos da Comissão Exploradora do Planalto Central do Brasil, a já mencionada Comissão Cruls (1892-1893), foi fundada para constituir instrumento tanto de crítica sistemática ao relatório Neiva-Penna quanto de defesa da salubridade do Brasil Central, 'conclusão médico-científica' que já teria sido preconizada pelos membros da Comissão chamados a testemunhar na revista contra a idéia do Brasil como "um imenso hospital".

Criada por Antonio Americano do Brasil, médico goiano formado no Rio de Janeiro, e Henrique Silva, militar goiano, membro da Comissão Cruls, visava, em sua periodicidade mensal, fazer propaganda do estado "mais central e menos conhecido do Brasil".

Contando também com a colaboração, na forma de artigos, de Capistrano de Abreu e Miguel Calmon, versava sobre vários assuntos, mesmo os políticos e econômicos da região; no entanto, à medida que crescia, na capital federal, o debate sobre o saneamento dos sertões mais seus artigos ganhavam teor médico. Assim, como já ressaltei, um dos temas mais discutidos, e combatidos e com muitos detalhes, era, naturalmente, o relatório NeivaPenna. Segundo editores e colaboradores da revista, os dois cientistas de Manguinhos seriam "os mais infatigáveis arautos da difamação das coisas goianas" ("Em favor de Goiás. Assunto sanitário", ago. 1920, p.3). Na verdade, a revista se apresentava como iniciativa dos "clínicos da roça" ("O Saneamento do hinterland", ago. 1918, p.9) em luta contra a "ciência oficial de Manguinhos", como era conhecido o Instituto Oswaldo Cruz na ocasião ("A ciência oficial no Brasil", maio 1918, p.131) para reverter a caracterização dos goianos como "tripanogoianos" (referência ao nome científico da doença da Chagas, a tripanossomíase americana) ou como os "exemplos mais bem acabados dos inúteis JecaTatus" ("Em favor de Goiás. Assunto sanitário", ago. 1920, p.3).

Nos números publicados sobretudo nos anos 20 o relatório Neiva-Penna foi muito criticado e frequentemente relacionado a outro relatório científico, já mencionado, o do doutor Antonio Azevedo Pimentel, médico da Comissão Cruls e que teria garantido, em finais do século XIX, ser Goiás uma das regiões mais salubres de todo o país. O próprio doutor Pimentel e o dr. Francisco Ayres da Silva, também médico goiano, eram dos colaboradores mais assíduos da revista. Defendiam que o Planalto Central seria região riquíssima - por seus minérios, vegetação, pastos para o gado, peixes e fontes de águas termais - e "salubérrima", onde não existiriam, por exemplo, indícios de tuberculose, gripe espanhola e impaludismo.

Ambos, como, aliás, os editores e demais colaboradores do periódico, em uníssono, além de negar que o sertão goiano fosse um "imenso hospital", alegavam que o maior problema da região era a falta de transportes e de comunicação com o restante do Brasil. Na verdade, Goiás padeceria, em sua visão, de dificuldades relacionadas à situação geográfica e não à falta de saneamento. 
A publicação do relatório Neiva-Penna em Memórias, depois de tantos debates e controvérsias em jornais e revistas, e em forma que lhes parecia ser de confirmação de 'verdade científica', ofendeu-lhes sobremaneira e aumentou a temperatura dos artigos da revista, como se pode acompanhar nos dois ilustrativos exemplos que se seguem e que fazem referência um ao artigo do Correio da Manhã de 23 de outubro de 1916 e o outro à publicação do relatório em Memórias em 1918, atribuindo a Oswaldo Cruz a responsabilidade pelo atraso em sua divulgação:

Em dezembro de 1916 o Correio da Manhã afirmou que estaríamos em maus lençóis se a capital do Brasil viesse um dia a ser localizada na área do planalto central, conforme deliberaram os legisladores constituintes.

E dizia que as notabilidades científicas de Manguinhos acabavam de lá encontrar o paludismo, a leishmaniose, a moléstia de Chagas e outras enfermidades perigosas.

O Diretor desta revista teve então oportunidade de endereçar àquele matutino uma carta, no mesmo dia, contestando em termos serenos e dizendo que nenhum médico desses poderia ter feito pesquisas nesse local e nem tampouco na área de $14.400 \mathrm{Km}^{2}$, escolhida para a capital do Brasil.

Publicada a carta, asseverou a redação do nosso confrade que o missivista laborava em grave erro, pois os Drs. Arthur Neiva e Belisário Penna lá estiveram em Comissão do Instituto de Manguinhos.

Em nova carta, o nosso Diretor provou que esses médicos não estiveram no sítio referido e que contra a sua salubridade se manifestaram apenas de oitiva e para acompanhar o terço dos que gritavam contra o estado sanitário do hinterland brasileiro.

O Correio deliberou não publicar essas provas, porque não lhe convinha destruir as capciosas afirmações da véspera nem tão pouco desmentir os emissários de Manguinhos... que se amoitaram.

Mas acaba de vir a lume nas Memórias do Instituto Oswaldo Cruz a tão sensacional Viagem Científica pelo Norte da Bahia, sudoeste de Pernambuco, sul do Piauí e de norte a sul de Goiás pelos Drs. Arthur Neiva e Belisário Penna para confirmar de vez que estes jovens cientistas na sua excursão nem se quer avistaram os lindes da área de $14.400 \mathrm{Km}^{2}$ demarcada pela Comissão Cruls para o futuro Distrito Federal da República! Como, pois, poderiam esses viajantes apressados fazer pesquisas científicas no local escolhido para a futura capital da União, achando-se este local no centro da aludida área geográfica?

Recordando o que aqui fica, não o fazemos com segunda intenção - e sim para não desertarmos do compromisso tomado no artigo de apresentação desta revista: "refutar com fatos e algarismos exatos as apreciações injustas que tantas vezes em livros e na imprensa se tem propalado acerca da terra goiana"

("A verdade sempre aparece", fev. 1918, p.80).

Os tão proclamados trabalhos acerca do Brasil Central, vindos à luz nestes últimos dias, e da lavra de alguns viajantes já laureados como jovens cientistas brasílicos, justificam plenamente o título destas linhas ... As passagens contraditórias, inverossímeis, enchem páginas da alentada "Viagem Científica". E, razão teve portanto o inolvidável saneador do Rio de Janeiro, não permitindo que o trabalho dos Srs. Arthur Neiva e Belisário Penna aparecesse nas "Memórias do Instituto Oswaldo Cruz". Reteve-a o sábio patrício na sua gaveta; e os que lhe eram íntimos talvez possam dizer os motivos. ("Viajores - mas superficiais observadores", mar. 1918$, p. 91$).{ }^{14}$

A publicação de Memórias reavivara a indignação com o artigo de 23 de outubro de 1916 do Correio da Manhã. Nesse encaminhamento, além de se oporem à linha geral de inter- 
pretação do relatório, ou seja, à ideia do 'sertão doente', os colaboradores da revista ainda faziam questão de listar supostos erros, e ínfimos, no texto de Neiva e Penna: teriam, por exemplo, atribuído sentidos equivocados a vocábulos próprios da região, teriam citado peixes de regiões goianas que sequer visitaram enquanto teriam deixado de mencionar a obrigatória 'vaca mocha', raça leiteira muito comum em todo o estado, a qual seguramente teriam visto se tivessem percorrido a região com atenção. Tantos 'erros' (mas a vaca mocha em especial) seriam indícios, segundo a revista, de que Neiva e Penna teriam superestimado consideravelmente as conclusões das pesquisas feitas em Goiás, estado sobre o qual, na verdade, pouco saberiam.

Dessas críticas nasceu campanha sistemática, e absolutamente ininterrupta, de 1919 a 1935, a partir da qual números inteiros da revista, ao destacar antes o 'isolamento da região', passaram a defender enfaticamente a transferência da capital federal para o interior, para o Planalto Central, para Goiás, conforme já rezava (e os editores repetiam esse ponto insistentemente) a própria Constituição do país. E era em favor de seu cumprimento que se posicionavam.

Asseguravam que, além de efetivamente constituir o "verdadeiro coração" do Brasil por ser o ponto mais central do território nacional entre o Pará e o Rio Grande do Sul, a capital, uma vez instalada em Goiás, disseminaria 'progresso' e 'civilização' em todo o interior do país. Asseguravam ainda que, pelejando pela transferência da capital, a revista estaria 'descobrindo' e revelando, aos demais brasileiros, as verdadeiras riquezas de Goiás, assim como Rondon teria feito com o Mato Grosso alguns anos antes. E, enquanto insistiam na defesa da mudança da capital como campanha patriótica em prol do sertão (campanha, segundo eles, aliás, mais autêntica e mais nacionalista do que o próprio movimento sanitarista ao qual se opunham), ganhavam adeptos e continuadores de sua causa: tanto os periódicos 'O Sertão' (1921), Correio Oficial (1911-1921), Goiás (1911-1922), Jornal de Goiás (1920-1921), O Lidador (1909-1917), Nova Era (1914-1919), A Imprensa (1914-1932), O Democrata (1923-1927), Voz do Povo (1927-1934) e Brasil Central (1937-1942) quanto a Sociedade Goiana de Geografia e História, fundada em 1921, e a Associação Universitária Goiana, criada em 1932. Também formularam e enviaram projetos de lei mudancistas ao senado em 1919 ("Um projeto apresentado no Senado", dez. 1919, p.59) e à comissão da Assembleia Constituinte, sob a presidência de Afrânio de Mello Franco, então ministro do Exterior ("O que se debata na comissão elaboradora da futura constituinte", nov. 1932, p.31; "Em defesa da localização da nova metrópole no Planalto Central", fev. 1933, p.53; "A mudança da capital da República: projeto de lei apresentado à Assembleia Constituinte”, nov. 1933, p.25), bem como conseguiram levar o tema a debate no VI Congresso Brasileiro de Geografia, realizado no Rio de Janeiro em 1920 ("Mudança da capital da República. VI Congresso Brasileiro de Geografia", fev. 1920, p.85).

Ainda que A Informação Goiana tenha deixado de circular por problemas financeiros e em função da morte de seu principal animador, o major Henrique Silva, pode-se dizer, no entanto, que seus artigos contribuíram, de maneira efetiva, para reavivar na agenda política brasileira a transferência da capital federal para o sertão goiano. Quanto mais não seja, entre as obras que apresentam o histórico do debate em prol da transferência da capital, seus editores e colaboradores são apresentados como "pioneiros de Brasília" (Vasconcelos, 1992). 


\section{Conclusão}

Os desdobramentos da campanha pelo saneamento rural nas políticas públicas de saúde e no debate sobre a identidade nacional vêm sendo analisados por importantes estudos em ciências sociais desde os anos 80 (Castro-Santos, 1985, 1987; Hochman, 1998; Lima, 1999, Lima, Hochman, 1996). A importância desse tema para o entendimento da história do Brasil na primeira metade do século XX tem sua pertinência redobrada em pesquisas que se ocupam, primordialmente, da criação de instituições de saúde pública para análise do processo de nation e state-building no Brasil e que partem da hipótese de que o tema da saúde foi central, de 1910 a 1960, para a realização de políticas públicas de extensão da cidadania e de expansão da autoridade pública no país (Lima, Hochman, 1996).

Nos pontos trabalhados por essas análises dos anos 80 e 90 aqui citadas encontram-se os potenciais de mobilização e apoio, intelectual e político, ao movimento pelo saneamento rural. Este artigo pretendeu aprofundar essa discussão ao investigar algumas críticas e oposições que o debate inspirou ou, ainda, as formas pelas quais os temas regionais, políticos e culturais, que giraram na órbita da discussão da doença como metáfora da identidade nacional, se seguiram filiando em justaposições frequentes por período tão prolongado. Desse modo, além de procurar contribuir para o entendimento da presença de temas do relatório em textos, entre outros, de Florestan Fernandes, Emílio Willems e Antonio Candido, nas décadas de 1940 e 1950 (Lima, 1999), procurei avaliar que papel tiveram as controvérsias e as interlocuções realizadas nas revistas em tão persistente maneira de interpretar os dilemas do país. Argumento que a interpretação só se tornou persistente porque os debates a ela relacionados foram alimentados nas revistas médicas, mas também e sobretudo, e por duas décadas, nas de letras e ciências.

E, ainda, para reforçar argumento já criticado na historiografia das ciências no Brasil, no artigo pretendi mostrar as maneiras pelas quais os ditos 'pré-científicos', ou os ensaístas brasileiros e autores menores cuja produção intelectual antecedeu a fundação de universidades no país, tiveram, na verdade, grande importância na formação e disseminação das ideias consagradas nos anos 30 e 40. Como as instituições na época eram de fato incipientes, boa parte de sua produção, assim como a promoção e divulgação de suas ideias, era feita por intermédio da imprensa, sobretudo pelas revistas (Sá, 2006). Quanto a isso, é preciso levar em conta as dificuldades na impressão tipográfica e a lentidão na distribuição dos livros, o que conferia à imprensa periódica da ocasião acentuada importância literária - seu trânsito e ampla circulação eram consideravelmente mais rápidos, e seus produtos, mais baratos.

A seguir essas obras e iniciativas, pode-se afirmar que as discussões suscitadas pelo relatório, sobretudo aquelas relacionadas à terapêutica popular, foram fundamentais para que as discussões intelectuais nos anos 20 e 30 reforçassem aspectos relacionados ao ambiente social e às instituições políticas brasileiras, e para que as análises dos anos 40 e 50 ganhassem forte cunho antropológico, com ênfase em questões de herança social e de cultura (Lima, 1999). Nesse quadro, doença e 'rotina' tornaram-se interpretações e representações intelectuais recorrentes do país. A atestar sua força, vimos toda a mobilização dos goianos em fazer-lhe frente por meio da campanha pela transferência da capital federal para o Planalto Central. Mais do que 'saúde', sua demanda era 'mudanças', insistindo em afirmar que o sertão, uma vez capital, entraria para a história do Brasil. 


\section{NOTAS}

* Este artigo é resultado de pesquisas no âmbito do projeto Uma Viagem, um Novo Brasil: o Relatório Científico de Arthur Neiva e Belisário Penna e sua Repercussão na Produção Intelectual Brasileira (19161940), desenvolvido em 2005-2008 com bolsa de pós-doutorado Prodoc/Capes junto ao Programa de Pós-Graduação em História das Ciências e da Saúde da Casa de Oswaldo Cruz/Fiocruz. O auxílio financeiro da Capes permitiu a contratação de Ludmila Gama, Tamara Rangel Vieira e Samara Mancebo, que coletaram e organizaram séries de informações para a pesquisa. A bolsista de iniciação científica PIBIC-CNPq Ingrid Casazza levantou séries de dados pertinentes ao trabalho, tendo também realizado a pesquisa com a revista Informação Goiana. Agradeço a todos os colegas do projeto Brasil Imenso Hospital, ao qual esta pesquisa esteve vinculada, especialmente Nísia Trindade Lima, Simone Kropf e Gilberto Hochman, pela intensa troca de ideias, bem como aos pareceristas anônimos deste artigo, que fizeram sugestões (quase) integralmente incorporadas à versão final do texto.

${ }^{1}$ Além dos livros e das teses acadêmicas, tal interesse pode ser atestado pelo lançamento, em importantes periódicos da área, de números especiais dedicados ao tema das viagens, assim como pela realização de simpósios e exposições sobre as relações entre ciência, diários de campo e representações do Brasil, como, por exemplo: Viagens e Viajantes, Revista Brasileira de História, v.22, n.44, 2002; Ciência e Viagens, História, Ciências, Saúde - Manguinhos, v.8, supl., 2001; o Colóquio Ciência, Civilização e Império nos Trópicos, promovido pelo Museu de Astronomia e pela Universidade do Estado do Rio de Janeiro em 2000; e a exposição A Ciência dos Viajantes: Natureza, Populações e Saúde em 500 anos de Interpretações do Brasil, promovida pela Casa de Oswaldo Cruz/Fiocruz, também em 2000.

${ }^{2}$ Essa imagem é de Roger Chartier (1998). Devo essa indicação a um dos pareceristas anônimos deste artigo.

${ }^{3}$ Relatório do Ministério dos Negócios da Indústria, Viação e Obras Públicas, 1892-1893. Disponível em: http://brazil.crl.edu/bsd/bsd/u2260/000009.html. Acessado em: 26 mar. 2008.

${ }^{4}$ Relatório da Inspetoria de Obras Contra as Secas. Ministério de Viação e Obras Públicas, 1911-1912. Disponível em: http://www.crl.edu/content.asp?11=4\&l2=18\&l3=33\&l4=22. Acessado em 21 jun. 2007.

${ }^{5}$ Relatório da Inspetoria de Obras Contra as Secas. Ministério de Viação e Obras Públicas, 1911-1912, op.cit.

${ }^{6} \mathrm{Na}$ documentação do Ministério da Viação sob a guarda do Arquivo Nacional, não há cópia do relatório ou qualquer menção a seu envio à Inspetoria de Obras Contra as Secas. Nos relatórios ministeriais não há tampouco referência ao envio do texto. Para a informação de que o texto final do relatório teria ficado pronto em 1915, ver o artigo de Simone Petraglia Kropf neste número.

${ }^{7}$ As pesquisas de Simone Kropf (2006) sobre a doença de Chagas revelam que estava em disputa, naquela segunda metade da década de 1910, a primazia na interpretação científica das então chamadas endemias rurais. Particularmente importante nesse debate era o quadro sintomatológico da doença de Chagas, que seu descobridor havia definido de forma bastante ampla: padeceriam do mal de Chagas até doentes mentais e portadores de bócio. Esse quadro clínico, alvo de ataques e muitas querelas médico-científicas (que envolveriam, aliás, médicos e cientistas brasileiros e argentinos), fazia da doença de Chagas o grande 'flagelo do sertão' na época. Segundo supõe Kropf, essa disputa científica teria causado o atraso na publicação do relatório, pois no mesmo número Chagas apresentaria dois artigos em que se defendia de seus críticos. De todo modo, é preciso salientar que não eram excepcionais os atrasos em publicações periódicas no início do século XX. Os anais e boletins da Academia Nacional de Medicina, por exemplo, tinham sua divulgação atrasada com bastante frequência.

${ }^{8}$ Gil Vidal, pseudônimo de Leão Veloso Filho, foi o primeiro redator-chefe do jornal (Leal, s.d.).

${ }^{9}$ Limitações de espaço impedem o comentário de todas as revistas pesquisadas. Optei por explorar a de maior periodicidade na época, a Revista do Brasil, em que os debates puderam ser acompanhados por vários números seguidos. Essa publicação ganha especial destaque neste artigo, como espécie de 'estudo de caso', pois minha proposta é avaliar e demonstrar as formas pelas quais os temas do relatório NeivaPenna ultrapassaram os círculos médicos, tendo sido discutidos por intelectuais de diferentes formações. A propósito, ver Luca, 1999.

${ }^{10}$ A propósito, ver o artigo de Nísia Trindade Lima publicado neste número.

${ }^{11}$ Entre esses textos, destacam-se "Notas à margem do relatório do dr. Arthur Neiva sobre o Norte" (Revista do Brasil, n.37, jan. 1919, p.59-71; n.38, fev. 1919, p.196-201; n.39, mar. 1919, p.311-314; n.40, abr. 1919, p.462-465; n.41, maio 1919, p.65-69; n.42, jun. 1919, p.169-176; n.48, dez. 1919, p.301-309), em que se ratifica a importância de Neiva como 'propagandeador independente' do relatório, mesmo 
após sua publicação em Memórias. Pelos temas mencionados e citados, nessas notas e em outros artigos das revistas, presume-se que a versão divulgada por Neiva fosse idêntica ou muito similar à versão publicada em Memórias.

12 Esses debates aparecem nos números 67, 69, 71, 74, 82, 83, 85, 87, 89, 93, 94 e 102 da Revista do Brasil.

${ }^{13}$ A revista foi localizada pela leitura de Magalhães, 2004.

${ }^{14}$ Como se sabe, o relatório foi de fato publicado em Memórias, e não temos elementos de pesquisa para especular sobre a suposta interferência de Oswaldo Cruz em atraso na edição do texto.

\section{REFERÊNCIAS}

ALBUQUERQUE, Marly et al.

A ciência a caminho da roça: Imagens das expedições científicas do Instituto Oswaldo Cruz ao interior do Brasil (1903-1911). Rio de Janeiro: Casa de Oswaldo Cruz/Fundação Oswaldo Cruz. 1991.

BARREIRO, José Carlos.

Imaginário e viajantes no Brasil do século XIX: cultura e cotidiano, tradição e resistência. São Paulo: Editora Unesp. 2002.

BIGIO, Elias dos Santos.

Cândido Rondon: a integração nacional. Rio de Janeiro: Contraponto. 2000.

BROCA, Brito.

A vida literária no Brasil - 1900. 3.ed. Rio de Janeiro: José Olympio. 1975.

CASTRO-SANTOS, Luiz Antonio de. Power, ideology and public health in Brazil (1889-1930). Tese (Ph.D) - Harvard University, Cambridge. 1987.

CASTRO-SANTOS, Luiz Antonio de. O pensamento sanitarista na Primeira República: uma ideologia de construção da nacionalidade. Dados - Revista de Ciências Sociais, Rio de Janeiro, n.28, p.193-210. 1985.

CHARTIER, Roger.

A aventura do livro: do leitor ao navegador conversações com Jean Lebrun. São Paulo: Unesp. 1998.

\section{CRUZ, Oswaldo}

Madeira-Mamoré Railway Company: considerações gerais sobre as condições sanitárias do rio Madeira. Rio de Janeiro: Papelaria Americana. 1910.

DIACON, Todd A.

Rondon: o marechal da floresta. São Paulo: Companhia das Letras. 2006.

FIGUEIRÔA, Silvia.

As ciências geológicas no Brasil: uma história social e institucional, 1875-1934. São Paulo: Hucitec. 1997.

FREYRE, Gilberto.

Precursores esquecidos. O Jornal, Rio de Janeiro. 21 jul. 1942.
GOMES, Sônia de Conti.

Bibliotecas e sociedade na Primeira República. São Paulo: Pioneira. 1983.

HALLEWELL, Laurence.

O livro no Brasil (sua história). São Paulo: Edusp. 1985.

HOCHMAN, Gilberto.

A era do saneamento: as bases da política de saúde pública no Brasil. São Paulo: Hucitec. 1998.

KROPF, Simone Petraglia.

Doença de Chagas, doença do Brasil: ciência, saúde e nação (19109-1962). Tese (Doutorado em História) - Universidade Federal Fluminense, Niterói. 2006.

KURY, Lorelai Brilhante.

Viajantes e naturalistas do século XIX. In: Pereira, Paulo Roberto (Ed.). Brasiliana da Biblioteca Nacional. Rio de Janeiro: Fundação Biblioteca Nacional. 2001a.

KURY, Lorelai Brilhante.

Viajantes-naturalistas no Brasil oitocentista: experiência, relato e imagem. História, Ciências, Saúde - Manguinhos, Rio de Janeiro, v.8, supl., p.863-880. $2001 \mathrm{~b}$.

\section{LEAL, Carlos Eduardo.}

Correio da Manhã. In: Abreu, Alzira Alves (Org.). Dicionário histórico-biográfico brasileiro. Rio de Janeiro: Centro de Pesquisa e Documentação de História Contemporânea do Brasil. Disponível em: http://www.cpdoc.fgv.br/ dhbb/verbetes_htm/5814_1.asp. Acesso em: 28 fev. 2008. s.d.

LIMA, Nísia Trindade.

Public health and social ideas in modern Brazil. American Journal of Public Health, Washington, v.97, p.1209-1215. 2007.

LIMA, Nísia Trindade.

Viagem científica ao coração do Brasil: nota sobre o relatório da expedição de Arthur Neiva e Belisário Penna à Bahia, Pernambuco, Piauí e Goiás. Revista da Fundação Museu do Homem Americano, Rio de Janeiro, v.1, n.3, p.185-215. 2003. 
LIMA, Nísia Trindade.

O Brasil e a Organização Panamericana de Saúde: uma história em três dimensões. In: Finkelman, Jacobo (Org.). Caminhos da saúde pública no Brasil. Rio de Janeiro: Opas. 2002.

LIMA, Nísia Trindade.

Um sertão chamado Brasil: intelectuais e representação geográfica da identidade nacional. Rio de Janeiro: Iuperj. 1999.

LIMA, Nísia Trindade; HOCHMAN, Gilberto. Pouca saúde e muita saúva: sanitarismo, interpretações do Brasil e ciências sociais. In: Hochman, Gilberto; Armus, Diego (Org.). Cuidar, controlar, curar: ensaios históricos sobre saúde e doença na América Latina e Caribe. Rio de Janeiro: Editora da Fundação Oswaldo Cruz. p.493-533. 2004.

LIMA, Nísia Trindade; HOCHMAN, Gilberto. Condenado pela raça, absolvido pela medicina: o Brasil redescoberto pelo movimento sanitarista da Primeira República. In: Maio, Marcos Chor; Santos, Ricardo V. (Ed.). Raça, ciência e sociedade. Rio de Janeiro: Fiocruz. p.23-40. 1996.

LIMA, Nísia Trindade; SÁ, Dominichi Miranda de. Science and territory in Brazil: the strategic Telegraph Commission of Mato Grosso to Amazonas (1907-1930). Minerva - Review of Science, Learning and Policy, London. no prelo.

LIMA, Nísia Trindade; SÁ, Dominichi Miranda de. No rastro do desconhecido. Revista de História da Biblioteca Nacional, Rio de Janeiro, v.11, p.18-23. 2006.

LUCA, Tânia Regina de.

A Revista do Brasil: um diagnóstico para a (N)ação. São Paulo: Unesp. 1999.

MACIEL, Laura Antunes.

A nação por um fio: caminhos, práticas e imagens da Comissão Rondon. São Paulo: Educ. 1998.

MAGALHÃES, Sônia Maria de.

Alimentação, saúde e doenças em Goiás no século $X I X$. Tese (Doutorado em História) -

Universidade Estadual Paulista, Franca. 2004.

MURARD, Lion; ZYLBERMAN, Patrick. La raison de l'expert, ou l'hygiène comme science sociale appliquée. Archives Européennes de Sociologie, Cambridge, v.26, p.58-89. 1985.

NEIVA, Arthur; PENNA, Belisário.

Viagem científica pelo norte da Bahia, sudoeste de Pernambuco, sul do Piauí e de norte a sul de Goiás. Memórias do Instituto Oswaldo Cruz, Rio de Janeiro, v.8, n.30, p.74-224. 1916.

ROSAS, Roberta Jenner.

Do paraíso ao grande hospital: dois olhares da ciência sobre o sertão (Goiás, 1892-1912). Dissertação (Mestrado) - Universidade de Brasília, Brasília. 1996.

SÁ, Dominichi Miranda de.

A ciência como profissão: médicos, bacharéis e cientistas no Brasil (1895-1935). Rio de Janeiro: Ed. Fiocruz. 2006.

SÁ, Dominichi Miranda de; SÁ, Magali Romero; LIMA, Nísia Trindade.

Telégrafos e inventário do território no Brasil: as atividades científicas da Comissão Rondon (1907-1915). Revista História, Ciências, Saúde Manguinhos, Rio de Janeiro, n.15, n.3, p.779810. 2008 .

SANTOS, Cláudia Penha dos.

As comissões científicas da Inspetoria de Obras Contra as Secas na gestão de Miguel Arrojado Ribeiro Lisboa (1909-1912). Dissertação (Mestrado) - Programa de Pós-Graduação em História das Ciências e da Saúde, Casa de Oswaldo Cruz/Fiocruz, Rio de Janeiro. 2003.

SHWEICKARDT, Júlio César; LIMA, Nísia Trindade.

Os cientistas brasileiros visitam a Amazônia: as viagens científicas de Oswaldo Cruz e Carlos Chagas (1910-1913). História, Ciências, Saúde Manguinhos, Rio de Janeiro, v.14, supl., p.15-50. 2007.

SOUZA LIMA, Antonio Carlos de. Um grande cerco de paz: poder tutelar, indianidade e formação do Estado no Brasil. Petrópolis: Vozes. 1995.

TAUNAY, Affonso D'Escragnolle.

Uma grande jornada científica: a viagem de Neiva e Penna. Revista do Museu Paulista, São Paulo, n.11, p.493-530. 1919.

VASCONCELOS, Adirson.

Os pioneiros da construção de Brasília. Brasília: Senado Federal. 1992.

VERGARA, Moema de Rezende.

Ciência e história no Relatório da Comissão Exploradora do Planalto Central na Primeira República. História, Ciências, Saúde -

Manguinhos, Rio de Janeiro, v.13, n.4, p.909925. 2006.

\section{$\rightarrow \rightarrow \gg<\leftrightarrow<$}

